Revista de Metalurgia 50(3)

July-September 2014, e023

ISSN-L: 0034-8570

doi: http://dx.doi.org/10.3989/revmetalm.023

\title{
On the feasibility of BLISK produced by linear friction welding
}

\author{
Antonio Mateo ${ }^{\mathrm{a}, \bowtie}$ \\ ${ }^{a}$ Departamento de Ciencia de los Materiales e Ingeniería Metalúrgica, Universitat Politècnica de \\ Catalunya - Barcelona Tech (UPC), Avda. Diagonal 647, 08028 Barcelona \\ Corresponding author: antonio.manuel.mateo@upc.edu
}

Submitted: 26 March 2014; Accepted: 24 June 2014; Available on line: 26 August 2014

\begin{abstract}
Friction welding technologies are solid-state processes that convert mechanical energy into heat at the joint to be welded. In the case of linear friction, interatomic diffusion takes place under compressive contact by rubbing one component across the face of the other. It is a relatively recent technology which has found important applications in the aeronautical sector. Specifically, it is applied by world leading aero-engine manufacturers for the fabrication of BLISK, a design where disk and blades are a single component. It is obvious that for such a critical function the reliability of linear friction welds must be totally guaranteed. The present work displays results concerning the characterization, both microstructural and mechanical, of a BLISK demonstrator designed for the intermediate pressure compressor of an aero-engine. Moreover, considering that the design constrains for disks and blades on the compressors are quite different, dissimilar titanium alloys were selected for each part in order to improve the BLISK in-service performance. The results establish that linear friction welding is a reliable process which can produce joints free of defects and with mechanical properties comparable to those of the corresponding base materials.
\end{abstract}

KEYWORDS: Aero-engines; BLISK (Bladed Disk); Demonstrator; Linear Friction Welding (LFW); Titanium alloys (Ti-6246 and Ti-64)

Citation / Cómo citar este artículo: Mateo, A. (2014) "On the feasibility of BLISK produced by linear friction welding". Rev. Metal. 50(3): e23. doi: http://dx.doi.org/10.3989/revmetalm.023.

RESUMEN: Sobre la viabilidad de los BLISK producidos mediante soldadura por fricción lineal. Las técnicas de soldadura por fricción son procesos en estado sólido que convierten la energía mecánica en calor en la junta a soldar. En el caso de la soldadura por fricción lineal, la coalescencia tiene lugar bajo un contacto compresivo producido rozando un componente contra otro. Se trata de una tecnología relativamente reciente que ha encontrado importantes aplicaciones en el sector aeronáutico. En concreto, los mayores fabricantes mundiales de motores de aviones la emplean para la fabricación de BLISK, un diseño en que disco y álabes son una única pieza. Es obvio que para una función tan crítica la fiabilidad de las soldaduras debe estar totalmente garantizada. El presente trabajo muestra resultados relativos a la caracterización, tanto microestructural como mecánica, de un prototipo de BLISK diseñado para el compresor de presión intermedia de un motor aeronáutico. Además, considerando que las requerimientos de diseño de discos y álabes son diferentes, se seleccionaron aleaciones de titanio disimilares para cada parte, para así mejorar el rendimiento del BLISK. Los resultados obtenidos demuestran que la soldadura por fricción lineal es un proceso fiable, que puede producir uniones libres de defectos y con propiedades mecánicas comparables a las de los correspondientes materiales base.

PALABRAS CLAVE: Aleaciones de titanio (Ti-6246 y Ti-64); BLISK (Bladed Disk); Motores aeronáuticos; Prototipo; Soldadura por fricción lineal

Copyright: (C) 2014 CSIC. This is an open-access article distributed under the terms of the Creative Commons Attribution-Non Commercial (by-nc) Spain 3.0 License. 


\section{INTRODUCTION}

The present introduction is divided in three parts. The first one explains what a BLISK (acronym for Bladed Disk) is; the second indicates the advantages of friction welding, whereas the last part is dedicated to Linear Friction Welding (LFW) applications and also to comment the aim of the work.

\subsection{Bladed Disk (BLISK)}

Aircraft engines are high-technology products whose manufacture involves novel techniques. Also, according to the conclusions of the External Advisory Group for Aeronautics of the European Commission (2000), aero-engines need a continuous improving of their technical capabilities to achieve higher efficiencies with regard to decrease fuel consumption and to enhance reliability and safety, while simultaneously meet restrictive environmental legislations.

In this framework, advanced compressor designs are essential to attain the purposes of engine manufacturers. Aircraft turbines commonly use compressor disks with individual blades anchored by bolts in a slotted disk hub. An alternative design is the BLISK, where disk and blades are fabricated in a single piece. Both designs are illustrated in Figure 1.

BLISK is an acronym from Bladed Disk, although the term IBR, from Integrated Bladed Rotor (IBR), is often used too. BLISK is one of the most original components in modern aero-engines. First used in small engines for helicopters, BLISK was introduced in the 1980's for military airplanes engines and it is rapidly gaining position in commercial turbofan and turboprop engines. The success of BLISK is due to its advantages, which are explained in the publications of Esslinger (2003) and Kermanpur et al., (2008). The main ones are:

- weight saving (usually as much as $20-30 \%$ ): resulting from the elimination of blade roots and disk lugs;

- improved aerodynamic efficiency: because BLISK diminishes leakage flows;

- suppression of the blade/disk attachment, whose deterioration by fretting fatigue is very often the life limiting feature.

Of course, BLISK have disadvantages too. The main one is the laborious, and then expensive, manufacturing and repairing processes. Also, an exhaustive quality control is required to ensure reliable performance.

BLISK can be produced by machining from a single forged slab or by bonding individual blades to a disk-like structure. Depending on the material and also on the design, factors that in turn depend on its location in the engine, each BLISK has its particularities that determine the selection of the manufacturing process. A complete description of the optimization process for BLISK design and manufacture is given by Bußmann et al., (2005).

In the low pressure stage of the compressor and the first stages of the high pressure part, where the length of the blade contributes significantly to the full diameter of the component, machining the BLISK is an expensive operation and also a lot of
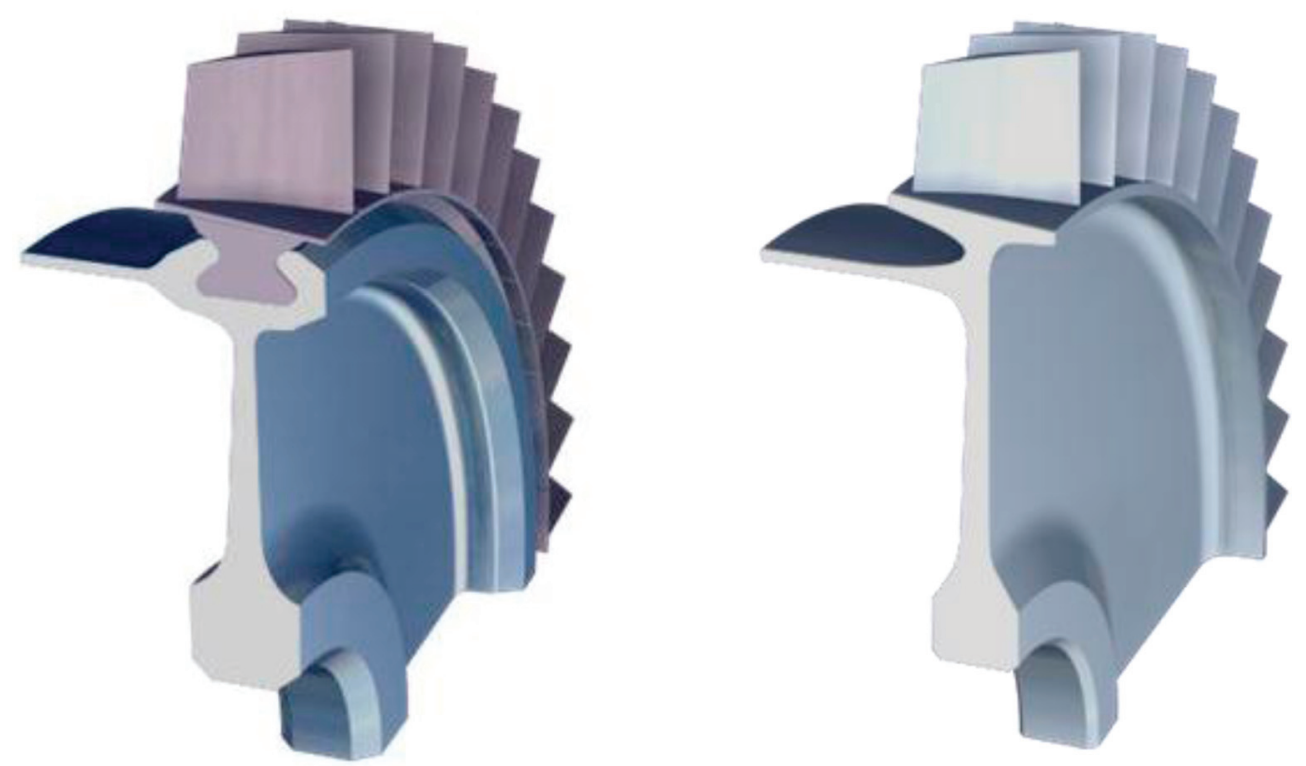

FIGURE 1. Illustrations of the mechanical attachment blade-disk (left side) and of a BLISK (right side). From Flightglobal website (2014). 
material is lost. Therefore, welding the blades one by one to the disk becomes more efficient. Roder et al., (2003) described the use of electron-beam welding and inertia welding for this application. Another interesting alternative is Linear Friction Welding (LFW).

\subsection{Welding by friction}

Friction welding enables joining of materials giving a weld of high integrity with many advantages over other joining methods. It is a solid state process as it does not cause melting of the parent materials. Heat is generated through mechanical friction between a moving workpiece and a stationary component. This frictional heating occurs at the interface between the parts, raising the temperature of the material to a level suitable for forging. Then, coalescence of materials takes place under compressive contact of the workpieces.

Several review articles, such as Nicholas (2003), Maalekian (2007), and Uday et al., (2010), describe the significant advantages of friction welding technologies as compared to other more conventional welding processes. Those advantages are:

- Being a solid state process, it does not suffer from inclusions and gas porosity.

- Creates narrow heat- affected zones.

- The process can be used to join many similar or dissimilar metal combinations.

- Full automation is possible, therefore the weld cycle is fully controlled by the machine, insuring joint quality and repeatability.

- Produces a $100 \%$ cross sectional weld area.

- Requires minimal joint preparation.

- No consumables such as filler material, fluxes or gases are required, consequently becomes more cost effective.

- Friction processes are at least two and even one hundred times faster than other welding techniques.

- Efficient utilization of the thermal energy developed.

- No post machining is needed for friction welded components in many cases.

- Suitable for quantities ranging from prototype to high production.

- Environmentally friendly process: no fumes, gases or smokes are generated.

The relative movement between the workpieces to joint can be rotation or linear, giving rise to the diverse friction welding processes. Rotary friction welding was the first of the friction processes to be developed and used commercially. In the 1980's, other friction techniques appeared, such as Friction Stir Welding (FSW) and LFW. In the FSW process, the friction is produced by a rotating tool tip that is plunged into the joint line between the two stationary pieces of sheet or plate material, which are butted together (Albuquerque et al., 2005; McNelley, 2010).

\subsection{Linear Friction Welding}

For LFW, the same principles apply as for rotary welding, i.e. one part is stationary while the other is moved and the two are brought together. The difference is that the moving component does not rotate, it oscillates laterally. This motion generates frictional heat resulting in softening of the material at the weld interface. Figure 2 depicts the schema of the LFW process.

Like all the other friction welding techniques, LFW is able to join materials below their melting temperature. The total cycle is very short, of the order of a few seconds, but four distinct stages are usually distinguished. Vairis and Frost (1998) gave a detailed explanation of those four phases. First, both parts are brought in contact under pressure. In the second or transition phase, workpieces are heated by the friction and the material reaches a plastic state. The third stage is called the equilibrium phase, when heat generated is conducted away from the interface and a plastic zone develops. Softened metal is expelled from the joint in the form of flash. As a consequence, significant axial displacement occurs. In the last step or deceleration phase, to complete the working cycle the oscillation amplitude decays until the total stop in times ranging from 0.2 to 1 seconds and the components are placed into perfect alignment. Once the amplitude of oscillation has decayed to zero, the axial load is maintained or increased. This forge stage has the effect of upsetting the plasticized material causing further axial displacement and consolidating the joint.

In the early 1980s, TWI (The Welding Institute) designed a prototype of electro-mechanical machine to demonstrate the viability of LFW technique. Since then, LFW has proved to be efficient for joining many different metals. Wilhem et al., (1995) presented its application to titanium alloys and Mary and Jahazi (2006) to nickel alloys. More recently, LFW of steels has been explored by Ma et al., (2007), while Ceschini et al., (2010) have done it for aluminium alloys. Even for dissimilar joints, such as welding copper to aluminium for electrical conductors, LFW feasibility was proved by Bhamji et al., (2010). According to Nunn (2005), the main drawback that restricts the expansion of this welding technique to more conventional applications is the elevated cost of the equipment.

LFW development has always been linked to aerospace industry. Its first important industrial use was for replacing damaged blades of aeroengines, as reported by Wilhem et al., (1995), showing that it is a process particularly appropriate for 


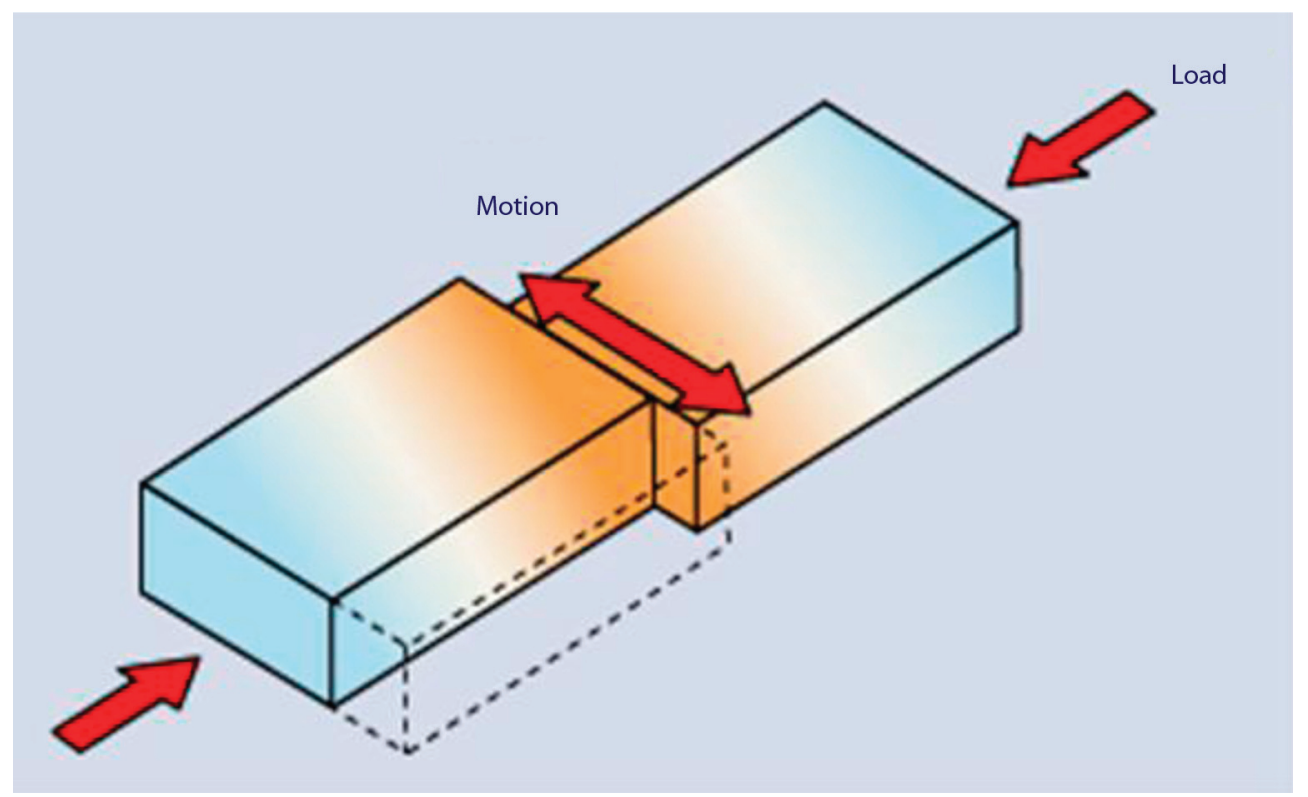

FIGURE 2. Illustration of the motion of the parts in the linear friction welding process. From Threadgill (2001).

welding titanium. The large affinity of titanium for oxygen, nitrogen and hydrogen makes that fusion welding must be carried out under inert gas atmosphere. Conversely, LFW avoids the formation of liquid phase and can be done in air.

The next logical step was to expand LFW application to titanium BLISK production. However, it is obvious that for such a critical purpose the reliability of LFW should be totally guaranteed. For that reason, an European R\&D Program called "Dual Material Titanium Alloy Friction Welded BLISK", acronym DUTIFRISK, was envisaged with the objective of characterizing the microstructure on the weld-zone and to determine the mechanical response of different combinations of titanium alloys selected to optimize BLISK performance. This research project, carried out from 2002 to 2006, included the production of BLISK demonstrators. The objective was to assess and validate LFW process on a real part scale. In the present article, the results from the characterization of one of the demonstrators are given and analyzed.

Also, other research efforts have been made in the last ten years to find the optimum process parameters to assure this reliability. For example, Wanjara and Jahazi (2005) tried to understand the impact of various processing parameters when welding Ti-64 and to define the optimum welding conditions. Attallah et al., (2009) analyzed the influence of an important LFW parameter, i.e. the forging pressure, on the microstructural development of Ti-6246. Also FEM (Finite Element Modelling) has been used as a predictive tool to optimize LFW processing parameters, as shown by Sorina-Müller et al., (2010).

\section{MATERIALS AND METHODS}

The reasons to select each particular Ti alloy for the disk and for the blades are explained in subsection 2.1. Henceforth, the production process of base materials is described in subsection 2.2. Subsection 2.3 presents the demonstrator manufacturing by LFW. Finally, the experimental methods to perform microstructural and mechanical characterization are explicated.

\subsection{Ti-alloys selection}

Titanium has two allotropic forms: $\alpha$ (with hexagonal closed packed crystal structure) and $\beta$ (cubic centered body structure). $\alpha$ and $\beta$ are the basis for the commonly accepted classification of Ti alloys in: $\alpha$, near- $\alpha, \alpha+\beta$, near- $\beta$ and $\beta$. These categories denote the microstructure after processing and heat treatment.

In aeroengine compressors, $\alpha+\beta$ alloys are mainly used for applications up to $300{ }^{\circ} \mathrm{C}$ because they offer an excellent combination of strength and ductility, whereas near- $\alpha$ alloys are preferred for more elevated service temperatures due to their better creep and oxidation resistance and near- $\beta$ have best formability and reach high strength levels.

On the other hand, the design constrains for disks and blades on the compressors are quite different. Whereas resistance to high cycle fatigue, foreign object impact and creep are the essential properties considered when selecting alloys for the blades, fatigue crack growth and low cycle fatigue are the dominating damage mechanisms for the disks. In the case of BLISK produced by machining, they 
are made wholly of the same alloy. Hence, disks and blades have the same microstructure, whose specific features are mostly selected regarding disk service conditions. In opposition, the use of the welding to manufacture BLISK opens the possibility of joining dissimilar alloys, choosing the most convenient $\mathrm{Ti}$ alloys and microstructures for each component, i.e. for disks and for blades, and therefore improving the in-service performance of compressors.

Following the approach explained in the last paragraph, for the present study Ti-6Al-4V (usually named $\mathrm{Ti}-64)$ was chosen for the blades, whereas Ti-6Al-2Sn-4Zr-6Mo (hereinafter named as Ti-6246) was used for the disk.

Ti-64 has a bi-modal $\alpha+\beta$ microstructure. It is a mature, standard alloy, mainly for applications up to $300{ }^{\circ} \mathrm{C}$. Besides, according to Peters and Lütjering (2001), Ti-6246 has a higher content of $\beta$-stabilising elements, mainly Mo and Cr, offering $10-20 \%$ a higher tensile strength than Ti-64.

\subsection{Base materials production}

In all cases, the diameter of the initial billets was 8 inches $(203 \mathrm{~mm})$. Nevertheless, subsequent manufacturing steps were different for the disk alloy and for the production of the blades. Ti-6246 for the disk was forged on a screw press at $980{ }^{\circ} \mathrm{C}$, temperature corresponding to the $\beta$-region, since the $\beta$-transus for this alloy is $945^{\circ} \mathrm{C}$. Heat treatment consisted in solution annealing at $915^{\circ} \mathrm{C}$ for 2 hours, with a forced air cooling, and finally ageing at $595{ }^{\circ} \mathrm{C}$ for 8 hours with air cooling. Finally, they were machined to produce the disks used in this investigation.

In the case of blade alloy Ti-64, billets were reduced through an open-die forging operation on a forging hammer and then a final pressing step was done in a screw press to the final shape, so-called "pancake", whose approximate dimensions were $600 \times 200 \times 60 \mathrm{~mm}$.

As a consequence of both the different chemical composition and those dissimilar forging conditions, two different microstructures were observed when the base materials for disks and blades were characterized by Scanning Electron Microscopy (SEM).

In the first case, Ti-6246 exhibited the typical aspect of a $\beta$-forged microstructure, with plateletlike $\alpha$-formation. This type of microstructure is often designated as lamellar. The age hardening treatment produced very fine $\alpha$-platelets in the $\beta$-matrix between the $\alpha$-plates (Fig. 3a). According to Lütjering and Williams (2003), this microstructure increases fracture toughness and fatigue crack growth resistance.

On the other hand, Ti-64 showed a bi-modal microstructure composed by globular $\alpha$ embedded in a fine lamellar $\alpha+\beta$ matrix (Fig. 3b). The content of $\alpha$ nodules was $45 \%$ and their mean size of $20 \mu \mathrm{m}$. The $\alpha$ lamellae are very fine and tangled within the $\alpha / \beta$ grains.

\subsection{BLISK demonstrator manufacturing}

As it was explained in the introduction, DUTIFRISK project included the production of BLISK demonstrators to validate LFW on a real part scale. To produce those demonstrators, the geometry of both disk and blades was simplified as compared to a real compressor stage, in order to reduce machining costs. Figure 4 consist of several images that illustrate the demonstrator production. Accordingly, Figure $4 \mathrm{a}$ is a schema of the idea of the demonstrator, where the replacement of blades by rectangular blocks is shown. A photograph of disk for the demonstrator, ready to be welded, is shown in Figure 4b. The "banana" shaped places or weld stubs, machined to be the faying faces to weld the individual blocks, are clearly seen. On the other hand, Figure $4 \mathrm{c}$ presents several of the blocks that simulated the blades in the demonstrator. The dimensions of these blocks, extracted from the central part of the pancakes, were $60 \times 36 \times 15 \mathrm{~mm}$. The "banana" shapes, analogous to those machined around the diameter of the disk, and destined to be the faying surfaces during the LFW process, are manifest.

Blocks were welded by linear friction to the disk in order to build the BLISK demonstrator. The appearance of the demonstrator BLISK with several blocks welded is shown in Figure 4d. The disk remained stationary during the welding process whereas the blocks oscillated. An electromechanical LFW machine was employed to execute the welds. This machine was set to produce the oscillation in the direction parallel to the shortest edge of the blocks. Previously to the welding, the faying surfaces were cleaned with acetone to remove any contaminating residues. Once clamped to the machine grips, the parts were brought together under load in order to ensure that they were correctly located in the tooling and that no undesirable axial movement would occur during the welding cycle. Then, they were separated and the block initiated the oscillation. Stationary disk and oscillating blocks were brought into contact and the friction force was applied until a set amount of axial shortening had occurred. At this time, the amplitude of oscillation was decayed over a set time period, bringing the parts into alignment. Once aligned, the forge force was applied for a set time period.

The magnitudes of the most significant parameters involved in LFW process, i.e. amplitude of oscillation, frequency, frictional pressure and burnoff, were selected from previous studies performed in the first work packages of DUTIFRISK project, as explained by Corzo et al., (2005).

\subsection{Characterization methods}

The present investigation focuses on the microstructural and mechanical characterization of the demonstrator welds. To perform these 
a)

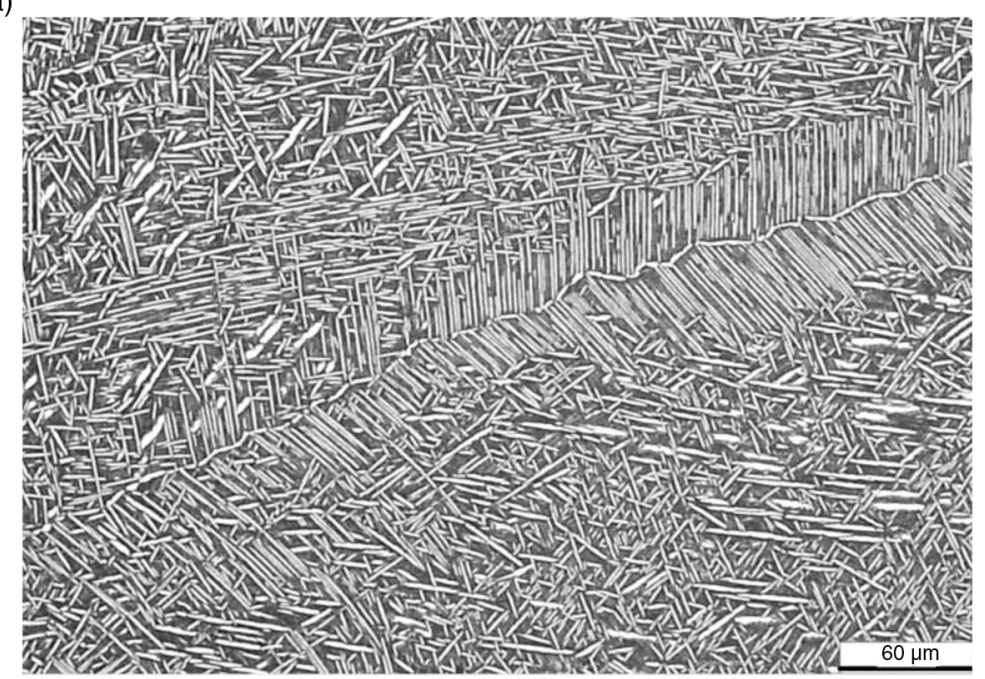

b)

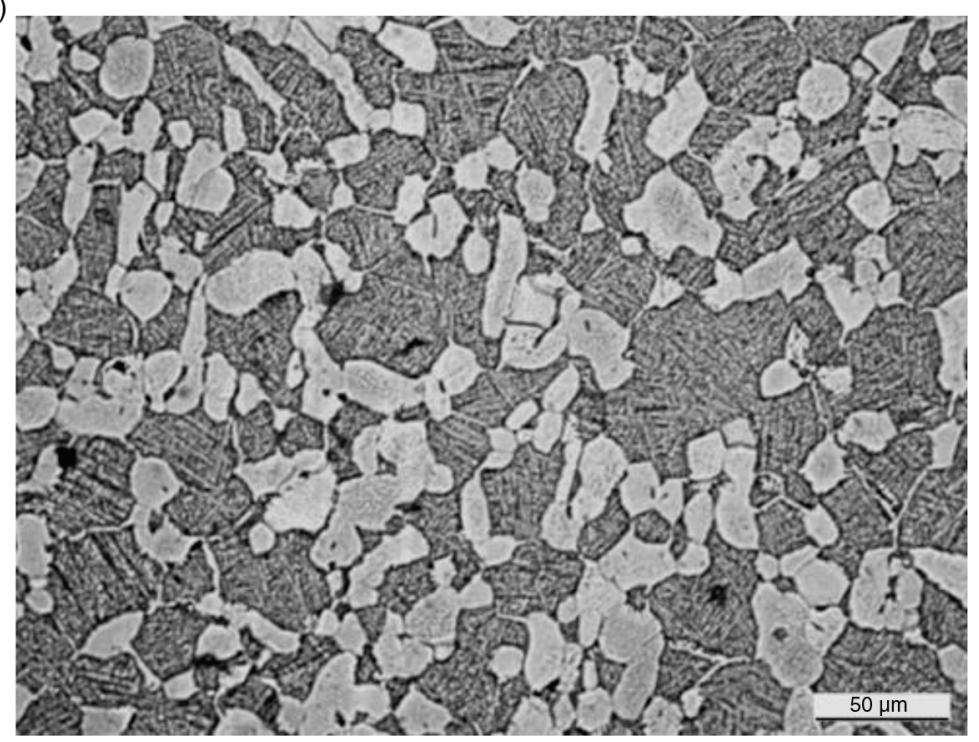

FIgURE 3. SEM images from the microstructure corresponding to alloys: a) Ti-6246 and b) Ti-64.

characterizations, portions were cut from the demonstrator. Those portions included the entire block corresponding to the blade, all the weld region and part of the disk material. They were post-weld heat-treated prior to be cut for the extraction of the specimen blanks for mechanical testing and for metallographic analysis. The post-welding heat treatment was performed during four hours at $620^{\circ} \mathrm{C}$ in vacuum. Mohandas et al., (2000) demonstrated that this heat treatment improves the weld properties.

Transversal cuts were performed in the central part of the portions extracted from the demonstrator. Samples were mechanically ground, polished and slightly etched with Kroll's reagent for optical microscopy analysis. Also Field EmissionSEM (FE-SEM) was used in order to discern microstructural features in the weld line.
The characterization performed in the present work to evaluate the mechanical response of LFW joints for BLISK manufacturing included tensile tests and hardness profiles along the weld joint. The first step for the characterization of the mechanical response of the welds was establishing the hardness profiles. For each specimen, hardness was measured across the weld region at the axial centerline, where the TMAZ (Thermomechanically Affected Zone) is narrower, using loads of $0.5 \mathrm{~kg}$ on a Vickers microhardness tester.

Tensile tests were performed for both base $\mathrm{Ti}$ alloys on cylindrical specimens of $6 \mathrm{~mm}$ in diameter. The same geometry was used to machine specimens extracted from the demonstrator portions, always with the load axis perpendicular to the joining plane of the weld. Tests were performed at room 
a)

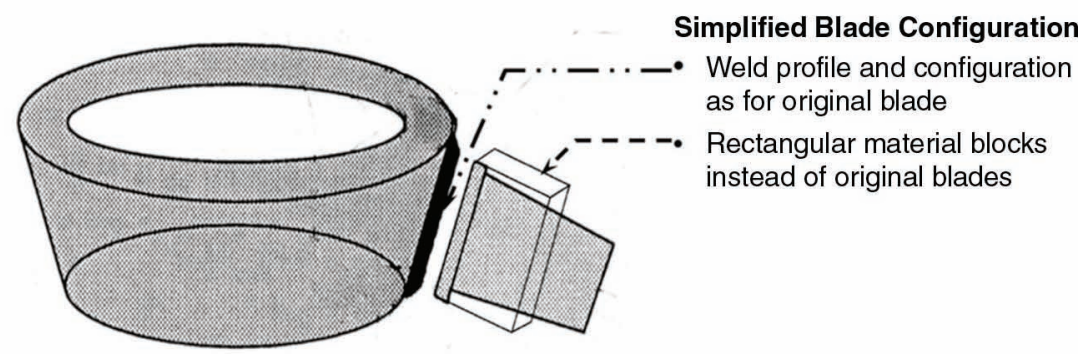

b)

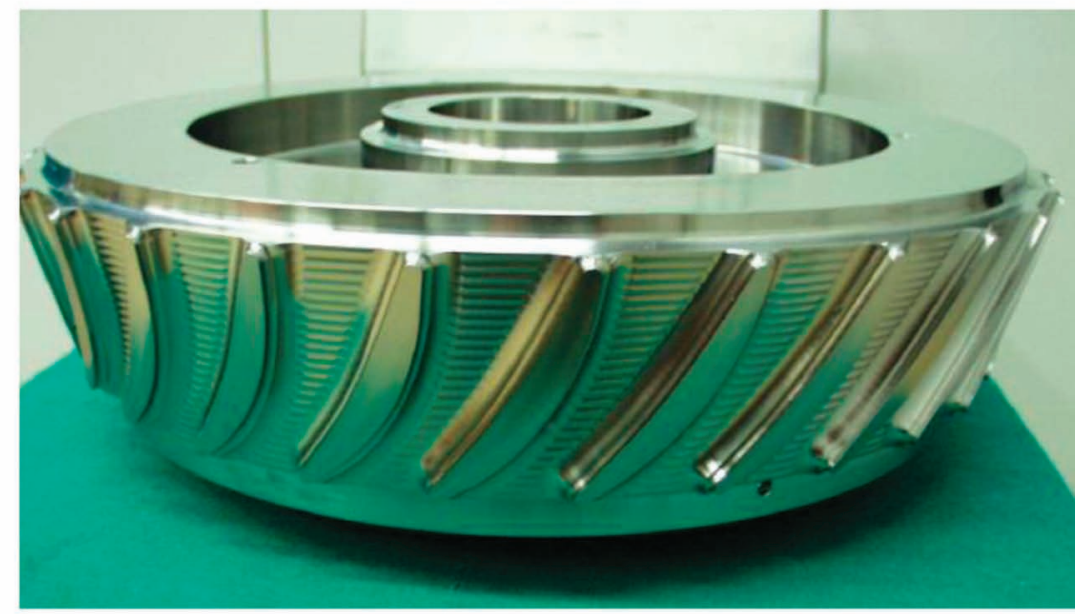

c)

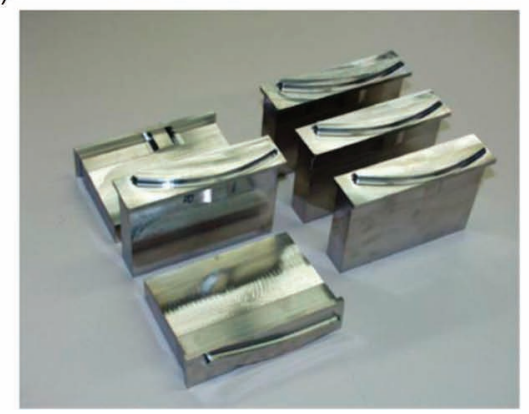

d)

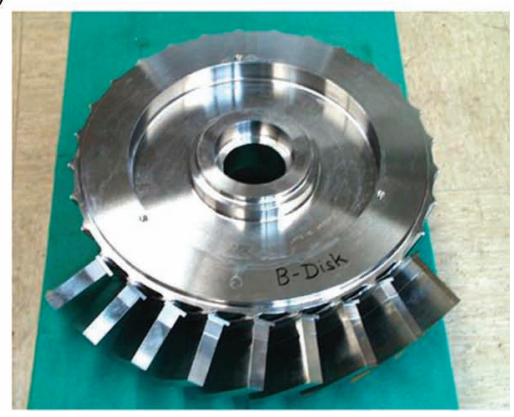

FIGURE 4. Illustrations of the BLISK demonstrator: a) Schema of the demonstrator configuration; b) Photograph of the machined disk for the demonstrator; c) Photograph of several machined blade-blocks for the demonstrator and d) Photograph of the BLISK demonstrator after welding several blade-blocks.

temperature and also at $300{ }^{\circ} \mathrm{C}$. This temperature was chosen as a typical service temperature for the intermediate pressure compressor stages. All the tests were performed under displacement control at a rate of $2 \mathrm{~mm} \mathrm{~min}^{-1}$ and at least two specimens for condition were tested.

\section{RESULTS AND DISCUSSION}

\subsection{Microstructural characterization}

Figure 5 shows an optical micrograph where the blade is in the upper part and the disk is placed in the lower one. From this image, two essential evaluation points regarding the joint quality were considered: flash type and corner defects.

The flash formed for the metal extruded from the plasticized interface by the oscillatory movement is clearly seen at both sides of the weld line. Different types of flashes may be observed in a component produced by LFW. The following notation is used to describe the type of flash: BF (Bifurcated), PBF (Partially bifurcated) and NBF (Non-bifurcated). As described by Nunn (2005), BF formations consist of two separate collars of flash protruding from the two workpieces. Usually, Ti alloys exhibit NBF formations where the burn-off material merges and the flashes from each weld half cannot be 


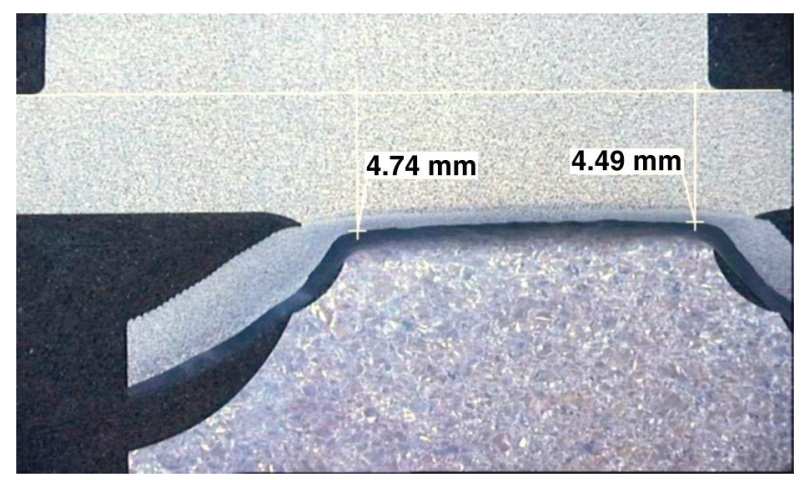

FIGURE 5. Optical micrograph of the weld interface. Ti-64 is in the upper part and Ti-6246 in the lower one.

distinguished by external visual examination. These flash formations are often long and wide. In the present case, the optical evaluation of the LFW blocks indicated that flashes were of NBF type. As shown in Figure 5, most of the flash is constituted by material from the blade part (grey color) whereas less than $20 \%$ of flash thickness came from the disk alloy (black color). This is reasonable because, as it will be explained later in section 3.2, the blade alloy, i.e. Ti-64, has a lower yield stress than the disk one, Ti-6246, and therefore the first one plasticized earlier during the LFW process.

An important aspect for the integrity of LFW components is the absence of defects located at the extremities of the weld, often called corner defects. They are usually associated with the preparation and alignment of the parts prior to welding. If the two parts to be welded do not match perfectly, when they are butted together the frictional heating in the edges does not occur at the start of the weld cycle and, as a consequence, hot plasticized material may flow around the corner rather than allowing the corner material to heat and flow itself. Nunn (2005) described two types of common corner defects: lack of bonding at the interface and tearing at the edge of the TMAZ away from the interface. None of these types of corner defects were detected in the present investigation. Moreover, other weld defects, such as cracks, voids or inclusions, were not detected.

Another critical factor to evaluate the quality of a LFW is the width of the TMAZ. Since the microstructure in the zone immediately adjacent to the weld line was not clearly discerned by optical microscopy, the characterization was mainly done by SEM. Figure $6 a$ is a collage, made with several micrographs, which exposes a global view of the weld center, the TMAZ and the parent materials. Far away from the weld line, i.e. more than $300 \mu \mathrm{m}$ from it, microstructures are those corresponding to the base alloys, apparently undeformed. Nevertheless, a microstructural evolution at both sides of the weld line is clearly noticeable, according to the temperature and plastic deformation reached at each point.

Figure $6 \mathrm{~b}$ makes the microstructural change evident for the blade side. At the left part of the picture, far from the weld, the typical bimodal microstructure of Ti-64 is observed. Then, when approaching the weld interface, the microstructural characteristics change and $\alpha$-nodules appear progressively more elongated following the oscillation direction.

Similarly, in the left part of Figure $6 \mathrm{c}$, the transformation of the lamellar microstructure corresponding to Ti-6246 is observed. Distortion of the $\alpha$-lamellae in the friction movement direction is perceived and the size of those lamellae is progressively reduced as the weld zone is approached.

Concerning the area closer to the weld line, there is a smooth transition and the microstructure becomes so fine that it cannot be resolved by SEM. Figure 7 depicts a high magnification view of this zone obtained by FE-SEM, just in the weld joint. Upper part corresponds to the blade side and the lower one to the disk alloy. Sorina-Müller et al., (2010) developed finite element simulations of the LFW, coupled with experimental data, which indicate that this fine microstructure is a consequence of rapid heating, severe plastic deformation and fast cooling to room temperature. Despite the short duration of the process (a few seconds), such a thermomechanical cycle induces temperatures higher than the $\beta$-transus in this part of the weld. Therefore, dynamic recrystallization occurs.

\subsection{Mechanical properties}

The advantages of welded BLISK will be factual only if their mechanical properties are good enough. These properties are difficult to predict because, as it has been explained in the precedent paragraph, the microstructure produced by joining two different alloys by LFW is very heterogeneous and rather different of the base materials. The mechanical characterization performed in the present work to evaluate the mechanical response of LFW joints for BLISK manufacturing included tensile tests and hardness profiles along the weld joint. Results are presented together with the mechanical properties of the base material titanium alloys, in order to discern a possible degradation on them as a result of the weld process.

\subsection{Hardness profiles}

For each specimen, hardness was measured across the weld region at the axial centreline. Figure 8 shows one of the obtained hardness profiles.

The hardness of the base materials gives the typical scatter band, with average values higher for the disk (around $370 \mathrm{HV}$ ) than for the blade (350 HV). This is reasonable, because Ti-6246 is a higher strength alloy than Ti-64. 
a)

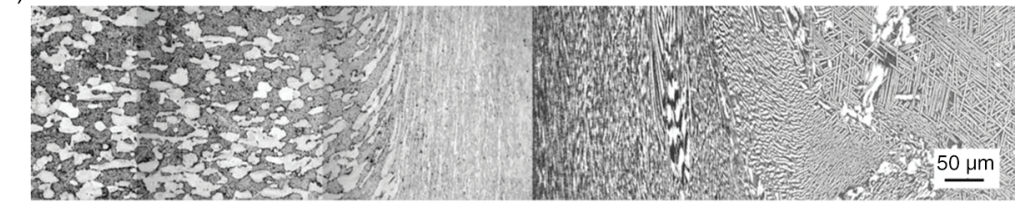

b)

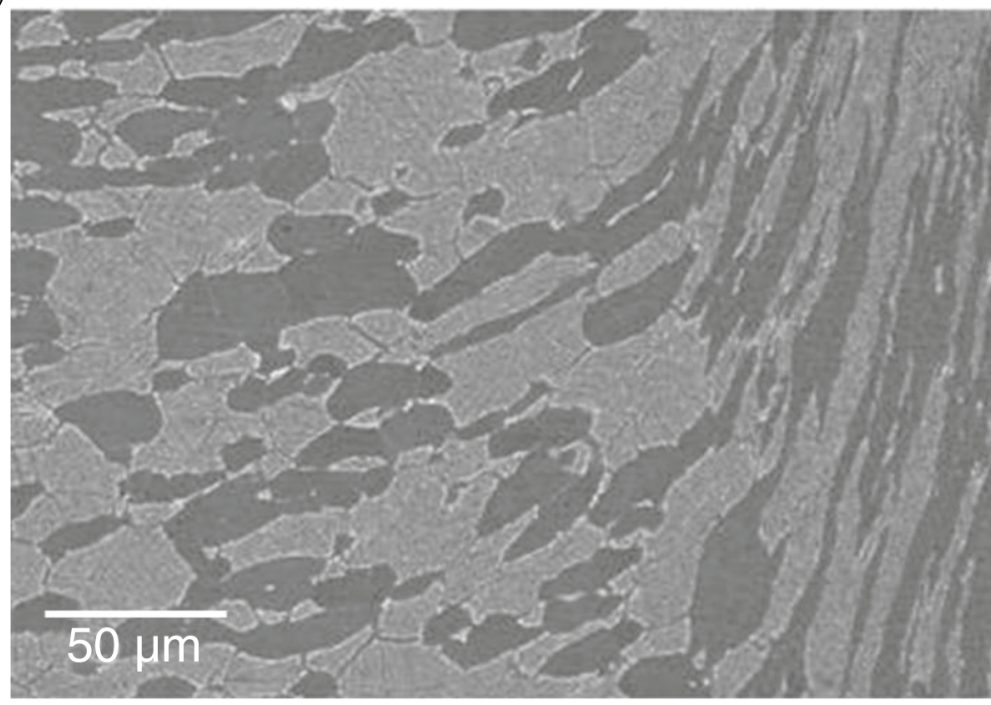

c)

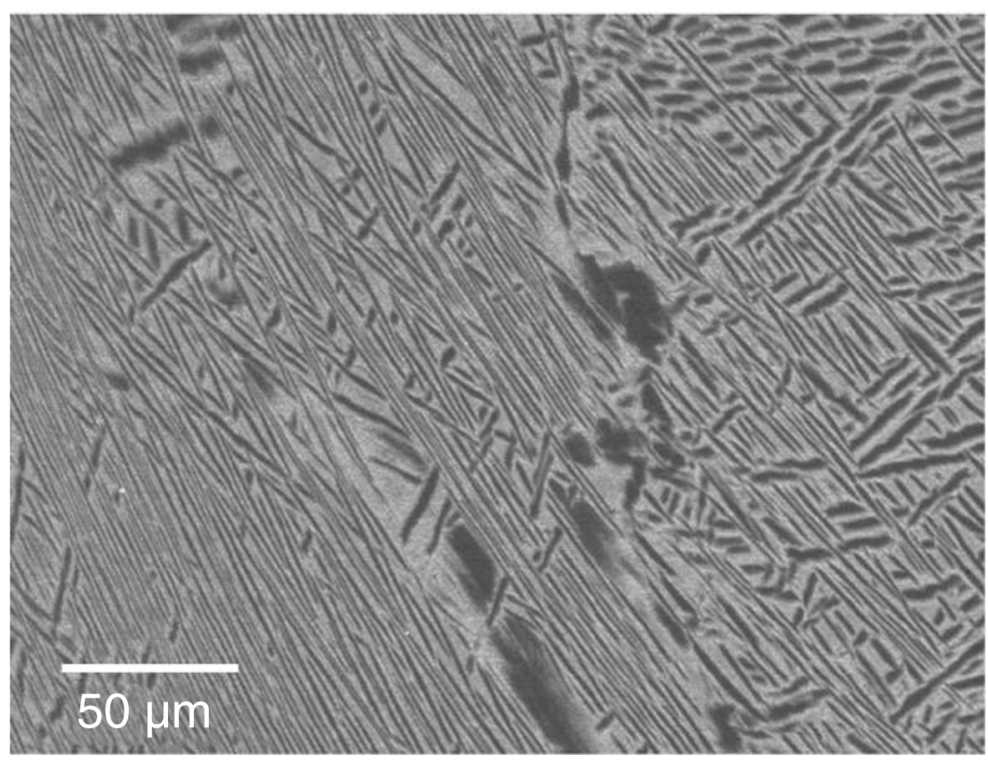

FIGURE 6. Microstructure of the welded zone: a) SEM collage of the microstructure in the weld center and thermomechanically affected zone. Blade material is at the left side and disk at the right one; b) Detail of the microstructure in the blade side when approaching the weld center (situated to the right side) and c) Detail of the microstructure in the disk side when approaching the weld center (situated to the left side).

On the other hand, hardness increases to a maximum value of $460 \mathrm{HV}$ that is reached directly in the weld plane. This value is similar to that obtained by Attallah et al., (2009), who studied LFW with Ti-6246 in both sides. The elevated hardness of this region is a consequence of the refinement of the microstructure described in subsection
3.1. A more detailed evaluation of the indentation response of these welds was given by Corzo et al., (2005).

Considering as a TMAZ all the portion of the joint harder than the base materials, its width can be established in approximately $1.5 \mathrm{~mm}$ in the disk side and $1 \mathrm{~mm}$ in the blade part. 


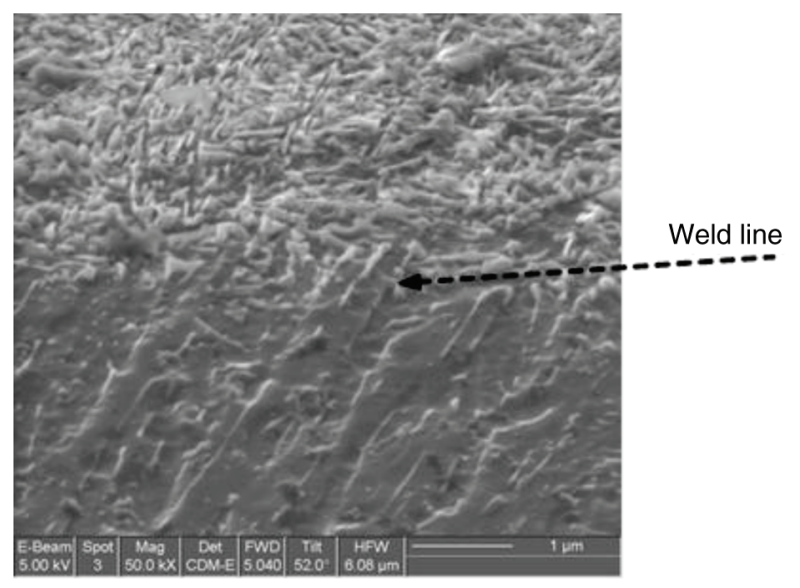

FIGURE 7. Microstructure in the weld zone observed by FE-SEM. Disk material is in the lower part of the image and blade material in the upper one.

\subsection{Tensile properties}

Table 1 summarizes the main results, including average values and their scatter. When the base materials properties are analysed, the higher strength of Ti-6246 as compared to Ti-64 becomes clear. Moreover, the differences between the yield stress and ultimate strength of both alloys become more marked at high temperature. Concerning ductility, Ti-64 exhibits more than double elongation to fracture than $\mathrm{Ti}-6246$, both at room temperature and at $300{ }^{\circ} \mathrm{C}$. All these experimental values are in the typical range reported for Donachie (2000).

For LFW specimens, it is important to note that fracture never took place by the weld zone, considering it as the weld centre plus the TMAZ. Moreover, all of the specimens failed in the blade parent material, at distances between 8 and $29 \mathrm{~mm}$ from the centre of the weld, as shown in Figure 9.

Tensile properties of the welded samples were close to the values obtained for the bimodal Ti-64 alloy. This is quite logical because it is the base material with the lowest strength and fracture always took place in that portion of the specimen, i.e. the blade part.

TABLE 1. Tensile testing results for base materials and welded specimens

\begin{tabular}{lcccc}
\hline Alloy & $\begin{array}{c}\text { Test } \\
\text { Temperature }\end{array}$ & $\begin{array}{c}\sigma_{\mathrm{ys}} \\
(\mathbf{M P a})\end{array}$ & $\begin{array}{c}\sigma_{\mathrm{uts}} \\
(\mathbf{M P a})\end{array}$ & $\begin{array}{c}\text { Elongation } \\
(\mathbf{\%})\end{array}$ \\
\hline Ti-6246 & Room & $1076 \pm 30$ & $1173 \pm 27$ & $8 \pm 1$ \\
Ti-64 & Room & $982 \pm 18$ & $1020 \pm 13$ & $20 \pm 1$ \\
Weld & Room & $991 \pm 5$ & $1029 \pm 2$ & $16 \pm 2$ \\
Ti-6246 & $300^{\circ} \mathrm{C}$ & $792 \pm 28$ & $996 \pm 41$ & $9 \pm 1$ \\
Ti-64 & $300^{\circ} \mathrm{C}$ & $645 \pm 44$ & $770 \pm 30$ & $19 \pm 1$ \\
Weld & $300^{\circ} \mathrm{C}$ & $630 \pm 4$ & $734 \pm 5$ & $13 \pm 2$ \\
\hline
\end{tabular}

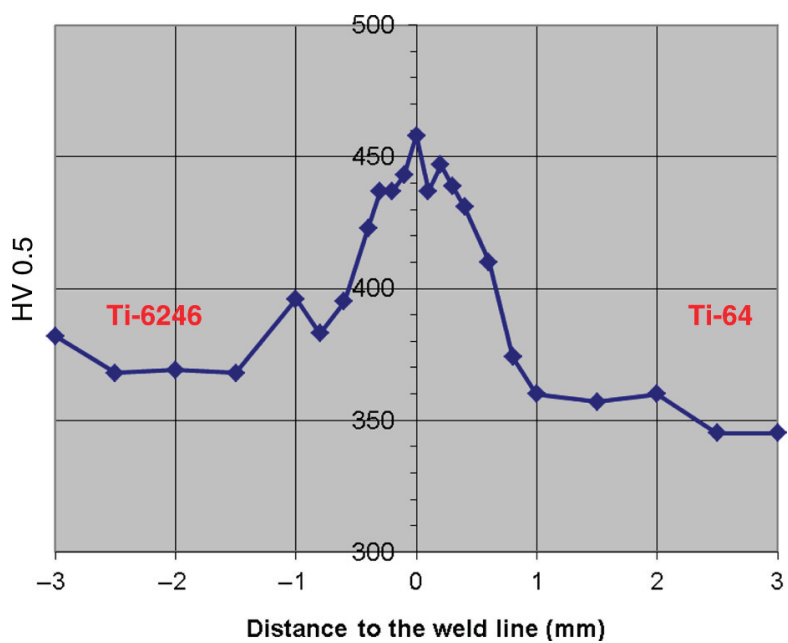

FIgURE 8. Microhardness profile on the welded area.

The mechanical property that seems to be the most affected one due the presence of the LFW was the elongation to fracture. Despite all the fractures occurred in the Ti-64 side and relatively far from the weld, the elongation was measured with an extensometer placed in the centre of the tensile specimen, i.e. their edges were equidistant from the weld line. Therefore, the Ti-6246 part of the specimen should contribute too to the total measured elongation. However, as the results of Table 1 clearly display, ductility of this alloy is reduced and, as a result, the total elongation of the tensile specimens machined from the demonstrator became lower than the corresponding values obtained on samples entirely made of Ti-64.

\section{CONCLUSIONS}

A demonstrator BLISK for the compressor of an aeroengine gas turbine was produced by linear friction welding. Two different titanium alloys were used for the disk and for the blades in order to optimize their respective in-service performance. Microstructural analysis showed a narrow thermomechanically affected zone, with a very fine microstructure. The mechanical characterization of the welded samples showed peaks of hardness in the weld centre. Tensile properties of welded samples

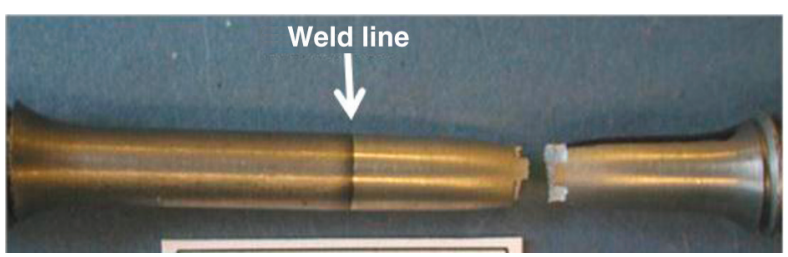

Figure 9. Photograph of a tested tensile specimen. Note the fracture at the right side, far from the weld line. 
are equivalent to those of the base material with the lowest strength, and fracture always took place in that part of the specimen far away from the weld.

The overall conclusion drawn from the research activities conducted on linear friction welding of $\mathrm{Ti}$ alloys for BLISK manufacturing is that this welding process is feasible and reliable to produce a dual alloy BLISK.

\section{ACKNOWLEDGMENTS}

The author wants to recognize to all the colleagues that participated in DUTIFRISK project: J.P. Ferte (SNECMA Moteurs), E. Gach (Böhler Schmiedetechnik), J. Méndez and P. Villechaise (ENSMA-CNRS), M. Nunn (TWI), M. Anglada and M. Corzo (CIEFMA-UPC) and particularly to the project coordinator O. Roder (MTU Aero Engines).

Also financial support of the European Commission (G4RD-CT-2001-00631, Acronym DUTIFRISK), Spanish Ministerio de Ciencia e Innovación (MAT2009-014461) and Generalitat de Catalunya (2009SGR1285) are acknowledged.

\section{REFERENCES}

Albuquerque, J., Ramos, R.A., Gomes, M.A., Cruz, A.C. (2005). Comportamiento a la fatiga de soldaduras por fricción lineal de AlSi $10 \mathrm{Mg}$. Rev. Metal. 41 (2), 126-132. http:// dx.doi.org/10.3989/revmetalm.2005.v41.i2.196.

Attallah, M.M., Preuss, M., Bray, S. (2009). Microstructural development during linear friction welding of titanium alloys. Proceedings of the 8th Int. Conf. Trends in Welding Research, Georgia, USA, pp. 486-491.

Bhamji, I., Preuss, M., Threadgill, P.L., Moat, R.J., Addison, A.C., Peel, M.J. (2010). Linear friction welding of AISI 316L stainless steel. Mater. Sci. Eng. A 528 (2), 680-690. http://dx doi.org/10.1016/j.msea 2010.09.043.

Bußmann, M., Kraus, J., Bayer, E. (2005). An Integrated CostEffective Approach to Blisk Manufacturing. Proceedings of 17th Symposium on Air Breathing Engines, ISABE, Munich, Germany

Ceschini, L., Morri, A., Rotundo, F., Jun, T.S., Korsunsky, A.M. (2010). A Study on Similar and Dissimilar Linear Friction Welds of $2024 \mathrm{Al}$ Alloy and 2124Al/SiCP Composite. $A d v$. Mater. Res. 89-91, 461-466. http://dx.doi.org/10.4028/ www.scientific.net/AMR.89-91.461.

Corzo, M., Casals, O., Alcala, J., Mateo, A., Anglada, M. (2005). Evaluación mecánica mediante técnicas de indentación de soldaduras por fricción lineal en aleaciones de titanio. Rev. Metal. 41 (6), 403-409. http://dx.doi.org/10.3989/revmetalm.2005.v41.i6.231.

Donachie, M.J. (2000). Titanium: A technical guide. ASM International, Ohio, USA

Esslinger, J. (2003). Proceedings of 10th Titanium World Conference, Lütjering, G., Albrecht, J. (Eds.), Vol. V, Munich, Germany, pp. 2837-2844.

External Advisory Group for Aeronautics of the European Commission (2000). Aeronautics for Europe, Office for Official Publications of the European Communities, Belgium.
Flightglobal website (2014). http://www.flightglobal.com/news/ articles/rolls-royce-tests-material-to-give-jsf-engine-somebling-214302/, June 2014.

Kermanpur, A., Sepehri Amin, H., Ziaei-Rad, S., Nourbakhshnia, N., Mosaddeghfar, M. (2008). Failure analysis of Ti6Al4V gas turbine compressor blades. Eng. Fail. Anal. 15 (8), 1052 1064. http://dx.doi.org/10.1016/j.engfailanal.2007.11.018.

Lütjering, G., Williams, J.C. (2003). Titanium. Engineering Materials and Processes, Springer-Verlag Berlin Heidelberg, Germany, pp. 224-232.

Ma, T., Li, W.Y., Quanzhou, X., Zhang, Y., Li, J., Yang, S., Liao, H. (2007). Microstructure evolution and mechanical properties of linear friction welded 45 steel joint. $A d v$. Eng. Mater. 9 (8), 703-707. http://dx.doi.org/10.1002/adem. 200700090.

Maalekian, M. (2007). Friction welding critical assessment of literature. Sci. Technol. Weld. Join. 12 (8), 738-759. http:// dx.doi.org/10.1179/174329307X249333.

Mary, C., Jahazi, M. (2006). Linear Friction Welding of IN-718 Process Optimization and Microstructure Evolution. $A d v$. Mater. Res. 15-17, 357-362. http://dx.doi.org/10.4028/ www.scientific.net/AMR.15-17.357.

McNelley, T.R. (2010). Friction stir processing (FSP): refining microstructures and improving properties. Rev. Metal. 46 ( ${ }^{\circ}$ Extra), 149-156. http://dx.doi.org/10.3989/ revmetalmadrid.19XIIPMS

Mohandas, T., Banerjee, D., Kutumba Rao, V.V. (2000). Microstructure and mechanical properties of friction welds of an $\alpha+\beta$ titanium alloy. Mater. Sci. Eng. A 289 (1-2), 70-82. http://dx.doi.org/10.1016/S0921-5093(00)00914-X.

Nicholas, E.D. (2003). Friction processing technologies. Weld. World 47 (11-12), 2-9. http://dx.doi.org/10.1007/ BF03266402

Nunn, M.E. (2005). Aero Engine improvements through linear friction welding. Proceedings 1st Int. Conference on Innovation and Integration in Aerospace Sciences, Belfast, Northern Ireland, U.K

Peters, J.O., Lütjering, G. (2001). Comparison of the fatigue and fracture of $\alpha+\beta$ and $\beta$ titanium alloys. Metal. Mater. Trans. A 32 (11), 2805-2818. http://dx.doi.org/10.1007/ s11661-001-1031-8.

Roder, O., Hem, D., Lütjering, G. (2003). Proceedings of 10th Titanium World Conference, Lütjering, G., Albrecht, J. (Eds.), Vol. V, Munich, Germany, pp. 2867-2874.

Sorina-Müller, J., Rettenmayr, M., Schneedfeld, D., Roder, O., Fried, W. (2010). FEM simulation of the linear friction welding of titanium alloys. Comput. Mater. Sci. 48 (4), 749 758. http://dx.doi.org/10.1016/j.commatsci.2010.03.026.

Threadgill, P.L. (2001). Linear friction welding. May be accessed at: http://materialteknologi.hig.no/Lettvektdesign/joining $\% 20$ methods/joining-welding-linear $\% 20$ friction $\% 20$ welding.htm.

Uday, M.B., Ahmad Fauzi, M.N., Zuhailawati, H., Ismail, A.B. (2010). Advances in friction welding process. Sci. Technol. Weld. Join. 15 (7), 534-558. http://dx.doi.org/10.1179/1362 $17110 X 12785889550064$

Vairis, A., Frost, M. (1999). On extrusion stage of linear friction welding of Ti-6Al-4V. Mater. Sci. Eng. A 271 (1-2), 477-484. http://dx.doi.org/10.1016/S0921-5093(99)00449-9.

Wanjara, P., Jahazi, M. (2005). Linear friction welding of Ti-6Al-4V: Processing, microstructure and mechanical property inter-relationships. Metall. Mater. Trans. A $36(8)$, 2149-2164. http://dx.doi.org/10.1007/s11661-005-0335-5.

Wilhem, H., Furlan, R., Moloney, K.C. (1995). Linear friction bonding of titanium alloys for aeroengine applications, Proceedings of the 8th World Conference on Titanium, Blenkinsop, P.A. et al., (Eds.), Birmingham, U.K., pp. 620-626. 